\title{
An Evaluation of OSPF and EIGRP Routing Protocols using OPNET Simulator
}

\author{
Ibrahim Mahdi Ibrahim ${ }^{\mathrm{a}}$ \\ a ibrahimmahdi@ksitm.edu.ng \\ School of Technology, Katsina State Institute of Technology and Management, P.M.B 2101 Katsina, Nigeria
}

\begin{abstract}
Routing protocols are the key for communication in a network. OSPF and EIGRP are dynamic routing protocols that are used in a network to propagate topology information to neighbouring routers. There are many dynamic and static routing protocols to be configured on a network but making the right choice of the protocol still remains an issue. This paper plans to study, compare and evaluate the network performance of EIGRP and OSPF routing protocols. In order to achieve accurate results, two network scenarios are designed and configured respectively with EIGRP and OSPF and are simulated to observe how the performance varies between the two protocols. This is measured based on four parameters: FTP, Web browsing (HTTP), E-mail and Database. The results derived from these experiments aims to provide better understanding on Interior gateway protocols and general knowledge on how or which routing protocol should be configured on a given network.
\end{abstract}

Published by IJRP.ORG. Selection and/or peer-review under responsibility of International Journal of Research Publications (IJRP.ORG)

Keywords: Open Shortest Path First (OSPF); Enhanced Interior Gateway Protocol (EIGRP); Discrete Event Simulation (DES); Routing Protocols; Network Performance.

\section{Introduction}

Routing is simultaneously the foremost complicated function of a network and therefore the most vital. Routing is the process routers perform when receiving packets, analyzing the destination address information, using the address information to pick a path for the packets, then forwarding the packet on to subsequent router on the chosen network. A packet use hops to reach next device on the network (McDonald et al, 2015). Packets can hop between different routers before reaching their final destination. At each hop, the router examines the destination IP address for every packet and therefore check the routing table for forwarding information.

Routing protocols are the key carriers for protocol data unit in any communication network. OSPF and EIGRP are dynamic routing protocols utilized in a network to disseminate topology information to neighbouring routers. There are an outsized number of dynamic and static routing protocols to be configured on a network but making the proper choice of the protocol still remains a problem. This research evaluates the network performance of EIGRP and OSPF routing protocols. In order to achieve accurate results, two network scenarios are designed and configured respectively with EIGRP and OSPF and are simulated to observe how the performance varies between the two protocols. This is measured based on four parameters: FTP, Web browsing (HTTP), E-mail (SMTP) and Database Access.

EIGRP routing protocol is often regard to as a hybrid protocol because it advertises its routing table 
to its neighbors as distance vector protocols do, however it uses the HELLO packets and creates neighbor relationships, similarly to link state protocols. Routers use EIGRPs' link discovery and recovery mechanism to learn about other routers on their network (X. Che et al, 2014). On the opposite hand, OSPF routing protocol is typically mentioned as hierarchical routing protocol thanks to its ability to divide large areas into small multiple areas. This includes the concept of area routers and edge routers. Area routers routes within a particular area while edge routers provide the potential for routing between the multiple areas (Gupta and Kaur, 2012).

Several simulations based studies were performed to gauge the performance of routing protocols on a Network using certain applications and parameters. However, most of those studies tends use the subsequent parameters (Convergence Time, Jitter, End-to-End Delay, Throughput, Video Conferencing and Voice Conferencing) to gauge the overall performance of the routing protocols. OSPF and EIGRP are the foremost common routing protocols used on the network, this study aims at providing the essential understanding of those routing protocols and provides a suggestion for optimal use while choosing routing protocols to get the ultimate performance through implementation. This is measured based on four parameters: FTP (File Transfer), Web browsing (HTTP), E-mail and Database (Access). This paper is organized as follows. Section 2 discusses the related work. Section 3 illustrates the Methodology of this work. Simulation results are discussed in Section 4, and Section 5 concludes the paper along with the future scope.

\section{Related Work}

Muhammad and Ashique (2016) performed a simulation based analysis of EIGRP and OSPF routing protocols based on real time applications. The comparative experiment was performed supported quantitative metrics (Convergence Time, Jitter, End-to-End Delay, Throughput and Packet Loss) on a proposed topology. Based on the results of their work, they proposed that network stability are often enhanced by reducing network convergence time of the routing protocol. Their results showed that EIGRP routing protocol features a much faster convergence time than OSPF routing protocol because EIGRP network learns about the topology information and sends updates faster than the OSPF.

Furthermore, based on their results ( Jaafar and Blair, 2015) proposed that the implementation of both EIGRP and OSPF routing protocols on a network performs better than implementing just one routing protocol on the network. This is due to the results of their simulations that show that End-to-End delay is relatively less; Delay variation is better; Packet Loss is less in a Network configured with both routing protocols. However, implementing both EIGRP and OSPF might make a network perform better, but this can only be on a large network and how about small networks? This requires higher implementation cost, higher CPU utilization and also requires the services of a network administrator with the knowledge of both EIGRP and OSPF routing protocols.

A comparative study by Yehia et al. (2011) proposed EIGRP routing protocol over OSPF routing protocol in terms of Network Convergence. Network convergence is the time it takes all routers in a network to recover back to operation after there is a change in the network topology (Basu and Rieke, 2008). The main focus of this study is to present a basic understanding of Interior gateway protocols regarding absolute best efficiency and to come up with a suggestion on how they can be used while choosing routing protocols to get faster convergence and improved performance. The authors pointed out that OSPF routing protocol has a better behaviour in terms of Route Addition compared EIGRP. The reason is that OSPF deals with fewer routes addition than EIGRP. They also point out that OSPF routing protocol performs better when it comes to route deletion, Hop updates and Time between Updates. The authors concluded that EIGRP found far better on basis of its good CPU utilization, less time consumption, better convergence performance and ease in management.

Effect of dividing OSPF Network into several areas in real-time applications was also studied by (Inderjeet and Sharma, 2011). This study focuses on the effect of OSPF areas on the quality of service of 
Voice over IP as an application layer level. According to their results, the authors found that dividing an OSPF autonomous system (AS) into independent routing areas allows topology abstraction, thereby reducing route overhead, table size and convergence time, at the same time providing an isolation from incorrect routing data. Furthermore, areas reduce connectivity thus increasing configuration complexity, routing path length and traffic concentration.

\section{Methodology}

This research followed a quantitative approach which involves the generation of knowledge in quantitative form which may be subjected to rigorous quantitative analysis following a formal and rigid fashion. The data collected is going to be tabulated and presented in consistent with the parameters utilized in the experiments. A simulation approach is adopted during which the network scenarios are going to be modeled using network simulation Tool. Discrete Event Simulation (DES) approach was adopted so as to evaluate the general performance of the routing protocol. OPNET IT Guru is built on top of discrete event system and it simulates system behavior by modeling each event within the system and processing it through user defined processes (OPNET, 2012). Figure 1 shows the research operational framework and the phases involved;

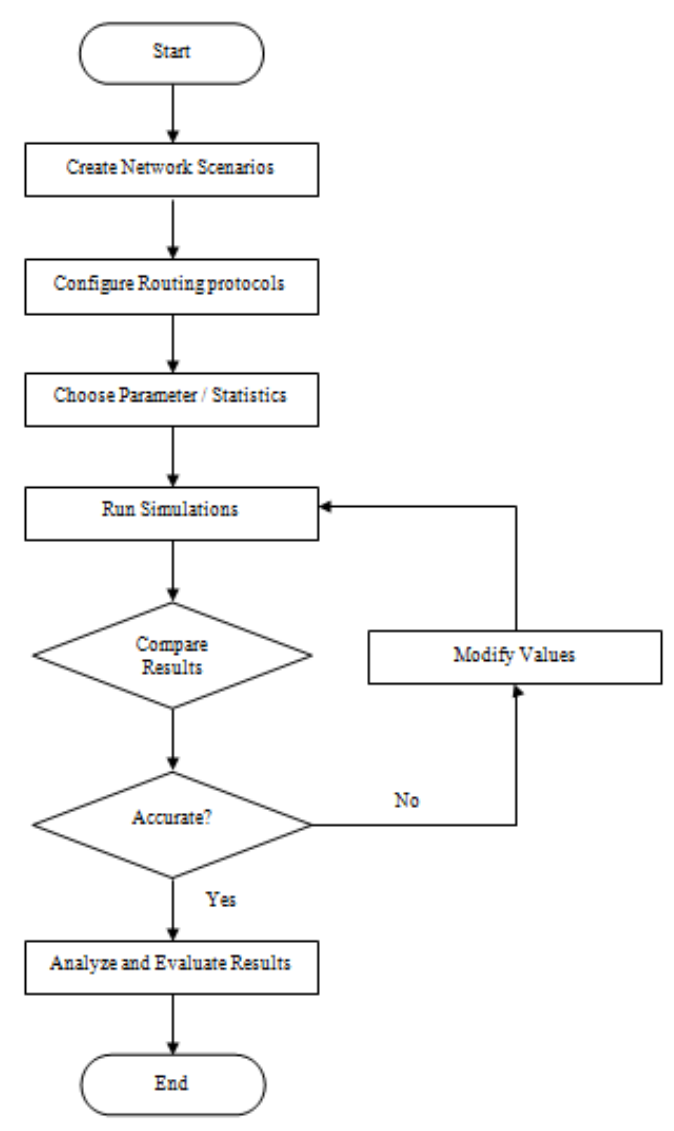


Fig. 1. Operational Framework

\subsection{Simulation Parameters}

The table below describes the relevant network Applications and Parameters used in performing the simulation experiments.

Table 1. Application Parameters

\begin{tabular}{lll}
\hline Application & Parameter & Unit \\
\hline Email & $\begin{array}{l}\text { E-mail upload } \\
\text { response time } \\
\text { E-mail download } \\
\text { response time }\end{array}$ & Seconds \\
& Seconds \\
& $\begin{array}{l}\text { FTP download } \\
\text { response time }\end{array}$ & Seconds \\
FTP & FTP upload \\
response time & Seconds \\
& & \\
HTPP & HTTP page & Seconds \\
& response time & \\
HTTP object & Seconds \\
& response time & \\
\hline
\end{tabular}

\subsection{OPNET Routing Protocol Model}

To achieve accurate results, two network topologies/scenarios were designed and configured with EIGRP and OSPF routing protocols respectively and are simulated to observe how the performance varies between the two protocols. This was measured using three (3) parameters: FTP, Web browsing (HTTP), and E-mail. The network topologies were modelled based on a Campus with several departments. Five departments and an admin block are considered when designing the network. All the departments contain routers, switches, a printer and workstations. An application object is configured with different applications to permit generating traffic to the network. The applications were defined within the profile definition object. A server is added to the topology and configured to support the preconfigured applications. 


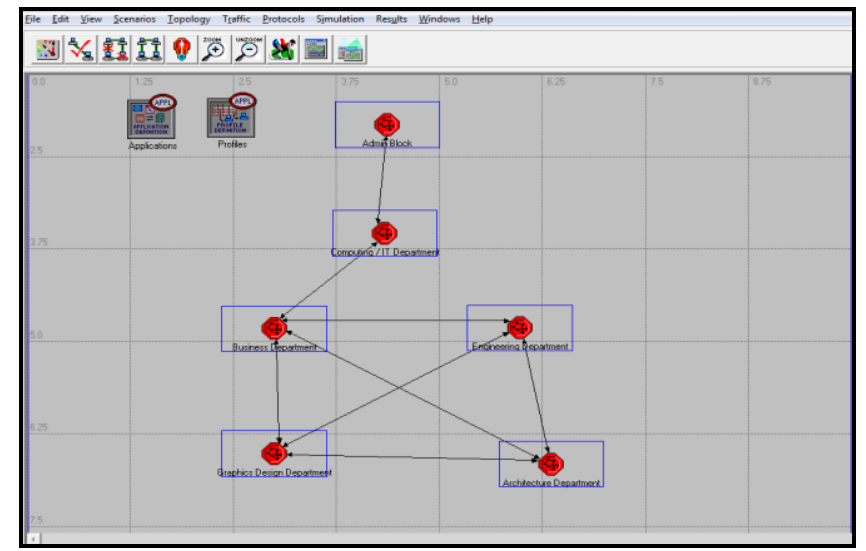

Fig. 2. OPNET network Topology

\section{Simulation Results and Discussion}

This section presents the comparative analysis and discussions on EIGRP and OSPF routing protocols. As mentioned earlier, two different scenarios were modelled to perform the experiment. One scenario is configured with EIGRP protocol and the other with OSPF protocol, each scenario is set to run simulation for 15 minutes. The data and statistics gathered from the simulation would be carefully analysed in this section. Figure 3 shows the HTTP Page Response Time for the two network scenarios. EIGRP page response time is recorded from $1 \mathrm{~min} 39 \mathrm{secs}$ to $14 \mathrm{~min} 50 \mathrm{secs}$. It has been noticed that at the starting point, it increases up to around $1 \mathrm{~min} 48 \mathrm{secs}$ and then decreases down at around $5 \mathrm{~min} 13 \mathrm{secs}$ from where it remains constant. Similarly, for OSPF, it is recorded from $1 \mathrm{~min} 38 \mathrm{secs}$ to $14 \mathrm{~min} 50 \mathrm{secs}$. It increases up at to $1 \mathrm{~min}$ 47 secs and decreases down at around $4 \mathrm{~min} 36 \mathrm{secs}$ from where it remains constant. This shows that OSPF routing protocol has a faster page response time than EIGRP routing protocol.

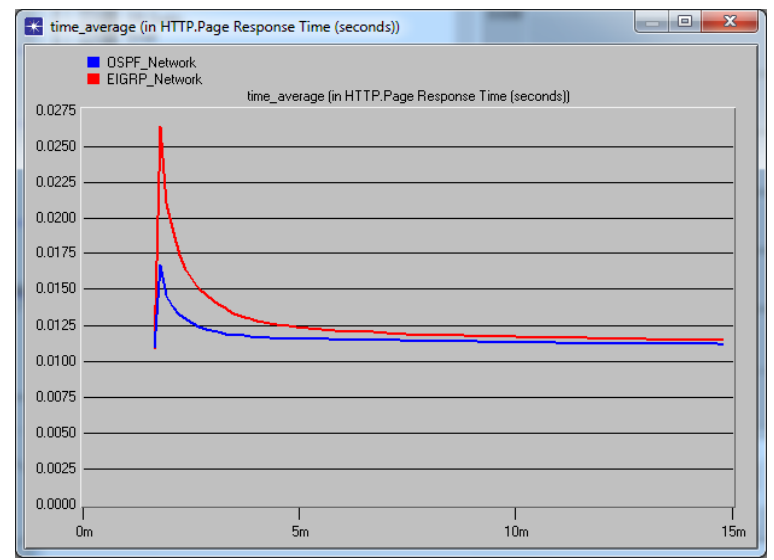

Fig. 3. HTTP page response time (sec)

In figure 4 the HTTP Object Response Time; OSPF is recorded from $1 \mathrm{~min} 38 \mathrm{secs}$ to $14 \mathrm{~min} 50 \mathrm{secs}$ and EIGRP with $1 \mathrm{~min} 39 \mathrm{secs}$ to $14 \mathrm{~min} 50 \mathrm{secs}$. OSPF has the faster object response time. 


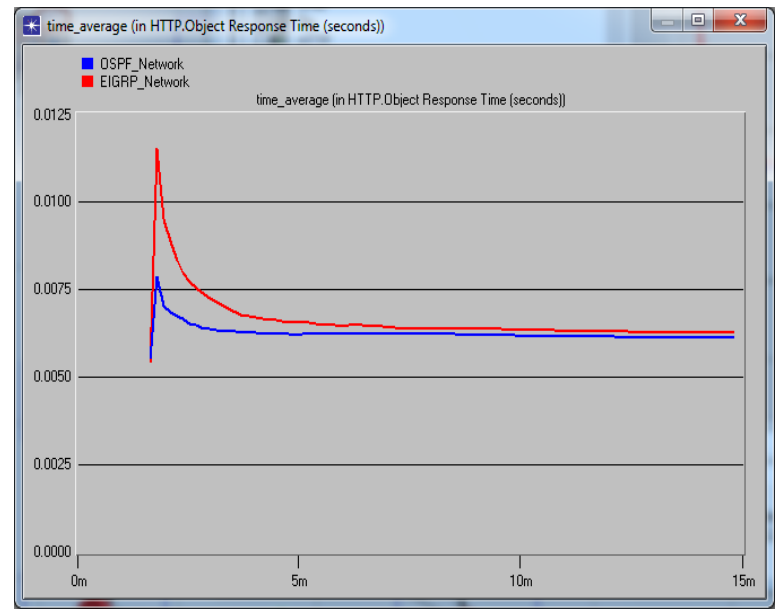

Fig. 4. HTTP object response time (sec)

In figure 5, OSPF FTP download response is recorded from $1 \mathrm{~min} 38 \mathrm{secs}$ to $14 \mathrm{~min} 50$ secs. From starting point, it increases to $1 \mathrm{~min} 48 \mathrm{secs}$ and decreases down to $2 \mathrm{~min} 22 \mathrm{secs}$. It starts increasing at $2 \mathrm{~min}$ $22 \mathrm{secs}$ and then decreases again at around $4 \mathrm{~m} 38 \mathrm{secs}$ from where it remained constant. In EIGRP network, the Download response time was recorded between $1 \mathrm{~min} 38 \mathrm{secs}$ to $14 \mathrm{~min} 50 \mathrm{secs}$, it increases up at $1 \mathrm{~min}$ $46 \mathrm{secs}$ and decreases down at $2 \mathrm{~min} 14 \mathrm{secs}$. It starts increasing again at $2 \mathrm{~min} 50 \mathrm{secs}$ from where it varies from time to time.

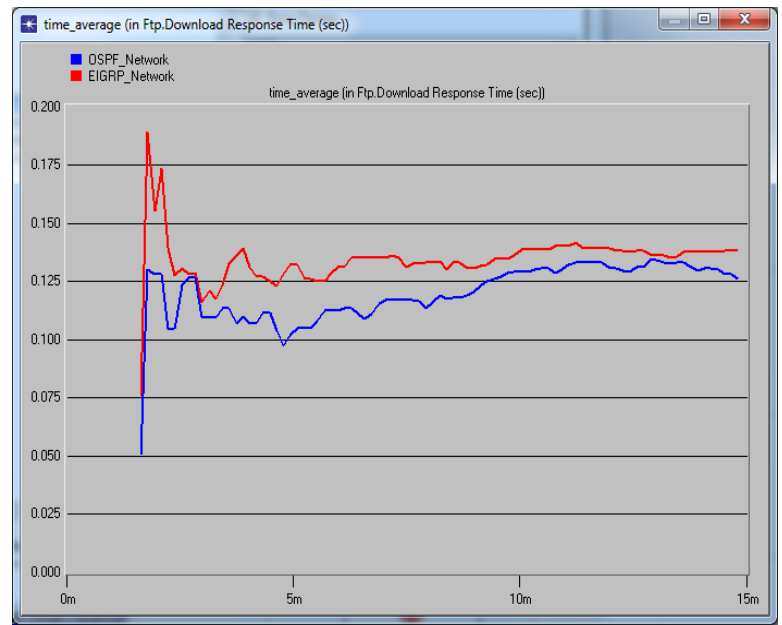

Fig. 5. FTP download response time (sec)

In figure 6, the FTP upload response time for EIGRP is recorded from $1 \mathrm{~m} 38 \mathrm{secs}$ to $14 \mathrm{~m} 50$ secs. From starting point, it increases up at $2 \mathrm{~m} 5 \mathrm{secs}$ and starts decreasing at around $2 \mathrm{~m} 50 \mathrm{secs}$. Another increase was noticed at around $4 \mathrm{~m} 48 \mathrm{secs}$ from where it starts to remain constant. OSPF is recorded from $1 \mathrm{~m} 38 \mathrm{secs}$ to $14 \mathrm{~m} 50 \mathrm{secs}$ also, it increases at $2 \mathrm{~m} 42 \mathrm{secs}$ and decreases at around $4 \mathrm{~m} 56 \mathrm{secs}$, from where it remains constant. This graph reveals that OSPF protocol is a little bit faster than EIGRP protocol because it has a steadier reading than EIGRP. 


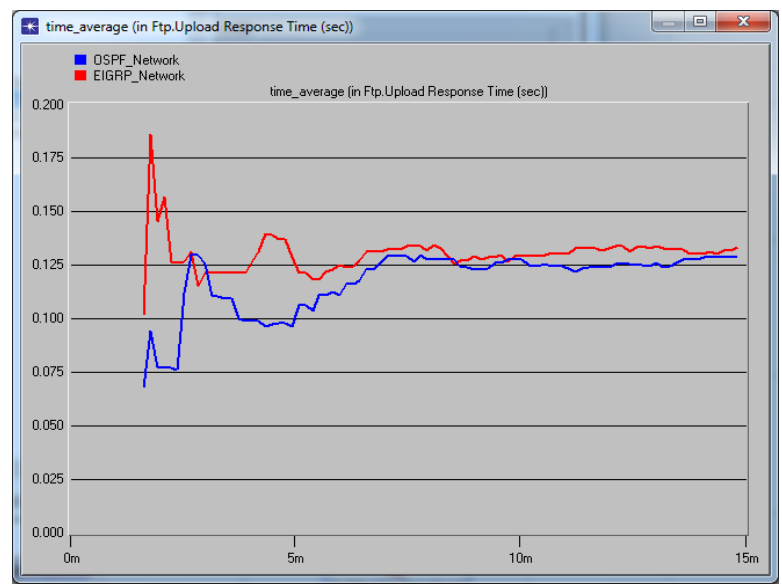

Fig. 6. FTP upload response time (sec)

In figure 7, the E-mail download response time of OSPF was recorded from $1 \mathrm{~m} 38$ secs to $14 \mathrm{~m}$ 50secs. It increases at $2 \mathrm{~m} 6$ secs and decreases down at $2 \mathrm{~m} 51 \mathrm{secs}$ from there it remains constant. In the network topology with EIGRP, E-mail download response time is recorded from $1 \mathrm{~m} 39$ secs to $14 \mathrm{~m} 50$ secs. An increase is observed at $1 \mathrm{~m} 47 \mathrm{secs}$ and decrease at $3 \mathrm{~m} 18 \mathrm{secs}$ from where it remains constant.

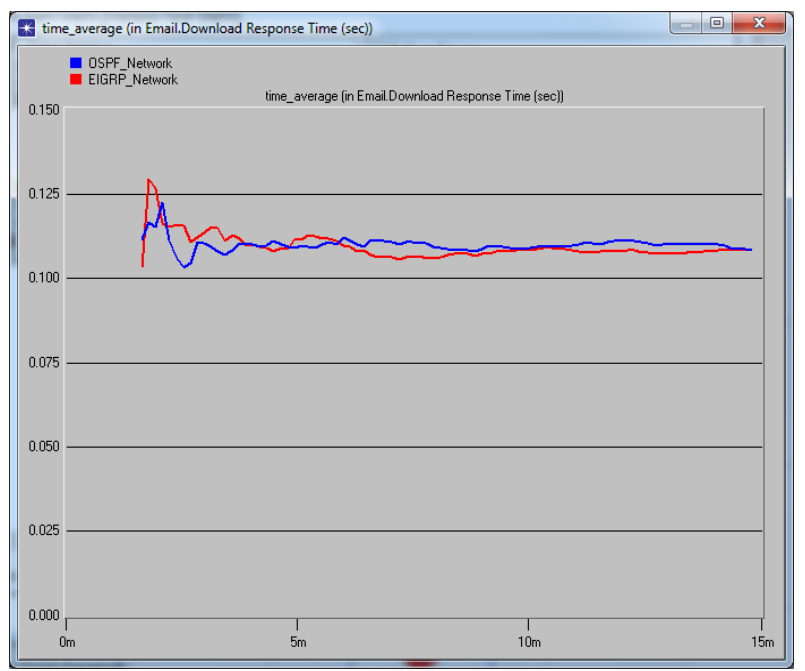

Fig. 7. E-mail download response time (sec)

In figure 8 , the EIGRP upload response time is recorded from $1 \mathrm{~m} 38 \mathrm{secs}$ to $14 \mathrm{~m} 50$ secs. From starting point, there is increase at $1 \mathrm{~m} 48 \mathrm{secs}$ and decreases at around $4 \mathrm{~m} 38 \mathrm{secs}$ where it continues to be constant. The upload response is recorded from $1 \mathrm{~m} 39 \mathrm{secs}$ with OSPF. It increases at $1 \mathrm{~m} 57 \mathrm{secs}$ from starting point and decrease at $4 \mathrm{~m} 48 \mathrm{secs}$ from where it remains constant. This show that Email upload response time is better with EIGRP routing protocol than OSPF protocol. 


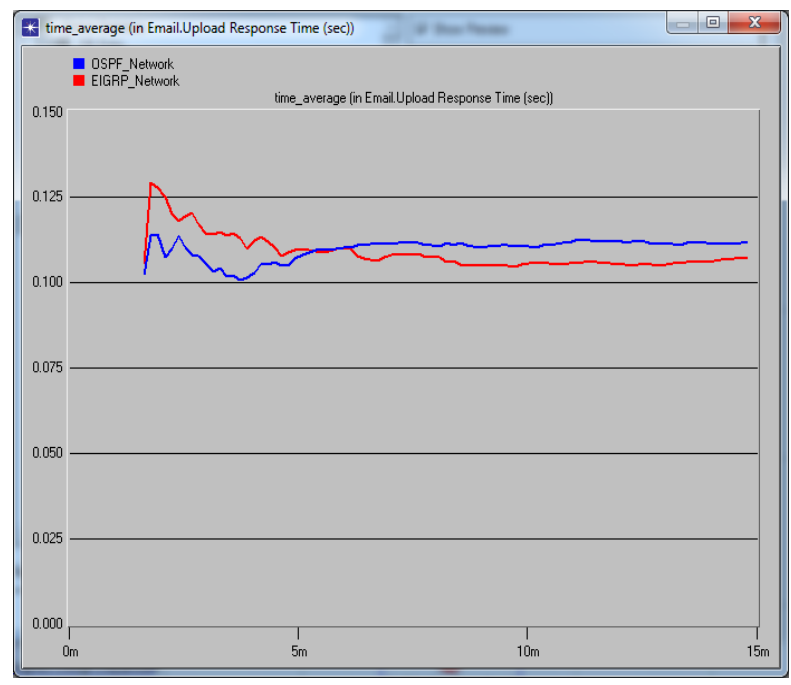

Fig. 8. E-mail upload response time (sec)

\section{Conclusion}

This paper has presented a comparative analysis and evaluation of EIGRP and OSPF Routing protocols. The comparative analysis and evaluation was performed on a campus network with different protocols using real time applications. The general performance of the two protocols were measured based on parameters that aimed to work out the consequences of implementing certain routing protocols. According to results obtained from the simulation using OPNET, the results of Web browsing (HTTP) shows that the Network topology having OSPF routing protocol features a faster page response time. Thus, it's also evident that the utilization of OSPF routing protocol is beneficial and recommended for Downloading and Uploading processes on the Network.

Another performance metric measured is Email Upload response time, which measures the time required to compose and upload an email on the Network. In this case, the results reveal that Network with EIGRP Routing protocol has a better performance than the OSPF Network. It has also been observed that, Database entry response time is better with EIGRP Network. Database entry response time is the time required for entry by the client to be stored into the server. However, in the case of Query response time, OSPF Routing has a better performance.

Based on the simulation experiment performed and the results that were achieved, OSPF routing protocol features a better performance than EIGRP protocol. Albeit the performance of every routing protocol is different from one another, the author recommends OSPF protocol to be useful on a campus network, not only in terms of network performance, but also in terms of configuration cost, because OSPF are often configured on any router where as EIGRP may be a proprietary protocol and may only be configured on a Cisco Device. 


\section{References}

Yehia and S. Aziz, A. Elsayed, 2011. Analysis of IGP Routing Protocols for Real Time Applications: A comparative Case Study. International Journal of Computer Applications, Vol. 26. No. 3.

McDonald, Rufi and Dye, 2015. Network Fundamentals: CCNA Exploration Companion Guide. Cisco Press, Indiana, p.167.

Xianhui Che, Lee J. Cobley, 2014. VOIP Performance over Different Interior Gateway Protocols.

Gupta Monika, Virpal Kaur, 2012. Open Shortest Path First Simulator by Using Java RMI. International Journal of Engineering Science and Technology. Vol. 2. No. 6.

Basu Anindya, Riecke G, 2008. Stability Issues in OSPF Routing. ACM SIGCOMM Computer Communication Review, 2008.

Mohammed Nazrul, Ashique Ahsan, 2016. Simulation Based EIGRP and OSPF Performance Analysis. International Journal of Computer Applications, Vol. 24. No. 8.

Jaafar and Blair, 2015. Simulation-Based Routing Protocol Performance Analysis - A Case Study. Proceedings of the Winter Simulation Conference, p.2154.

Inderjeet Kaur, Manju Sharma, 2011. Performance Evaluation of Hybrid Network Using EIGRP and OSPF for Different Applications. International Journal of Engineering Science and Technology, Vol. 3. No. 5. 